\title{
The Modification of the Martin-Hou Equation of State and its application in Liquid-phase State
}

\author{
Zhicong Chen ${ }^{1}$, Guang Yao ${ }^{1}$, Quan Zhu ${ }^{1}$, Jianli Wang ${ }^{1}$, and Xiangyuan $\mathrm{Li}^{1}$ \\ ${ }^{1}$ Sichuan University
}

May 5, 2020

\begin{abstract}
In order to further improve the calculation precision and get a simpler algorithm, the Martin-Hou Equation of State is modified after rigorous data analysis data in different cases. A new revision factor $\mathrm{h}$, a function of critical compression factor, is introduced into the novel M-H EOS to reduce the deviation of molar volume calculated in liquid-phase state. According to the new derivation process of the EOS, only a few number of physical properties are needed to characterize a given substance, which greatly reduced the difficulty of solution of the EOS. In order to verify the generality and the calculation precision in liquid-phase state, the novel M-H EOS has been applied to six representative substances: argon, methane, nitrogen, propane, benzene and water. Compared with the previous M-H EOS in liquid-phase state, the novel M-H EOS obviously reduces the deviation and can universally be applied to most kinds of substances.
\end{abstract}

The Modification oftheMartin-Hou Equation of State and its applicationin Liquid-phaseState Zhicong Chen. ${ }^{\mathrm{a}, \mathrm{b}}$ Guang Yao. ${ }^{\mathrm{a}, \mathrm{b}}$ Quan Zhu. ${ }^{\mathrm{a}, \mathrm{b} *}$ Jianli Wang, ${ }^{\mathrm{b}, \mathrm{c}^{*}}$ and Xiangyuan Li ${ }^{\mathrm{a}, \mathrm{b}}$ ${ }^{a}$ School of Chemical Engineering,Sichuan University, Chengdu 610064, Sichuan, P.R. China

${ }^{b}$ Engineering Research Center of Combustion and Cooling for Aerospace Power, Ministry of Education, Sichuan University, Chengdu, Sichuan 610065, P.R China;

${ }^{c}$ College of Chemistry, Sichuan University, Chengdu 610064, Sichuan, P.R. China

${ }^{*}$ Corresponding author: Quan Zhu, Email: qzhu@scu.edu.cn; Jianli Wang, Email:

wangjianli@scu.edu.cn; Tel/Fax: +86-028-85418451.

ABSTRACT:In order to further improve the calculation precision and get a simpler algorithm, the MartinHou Equation of State is modified after rigorous data analysis data in different cases. A new revision factor $h$, a function of critical compression factor, is introduced into the novel M-H EOS to reduce the deviation of molar volume calculated in liquid-phase state. According to the new derivation process of the EOS, only a few number of physical properties are needed to characterize a given substance, which greatly reduced the difficulty of solution of the EOS. In order to verify the generality and the calculation precision in liquidphase state, the novel M-H EOS has been applied to six representative substances: argon, methane, nitrogen, propane, benzene and water. Compared with the previous M-H EOS in liquid-phase state, the novel M-H EOS obviously reduces the deviation and can universally be applied to most kinds of substances.

Keywords: the M-H EOS, liquid phase, precision, derivation, characteristic constant.

\section{INTRODUCTION}

The research of equation of state (EOS) has always been an important field in chemical engineering thermodynamics. In general, EOS can be divided into the specific EOS for a given substance and the general EOS 
for many kinds of substances ${ }^{1-3}$. Differently, the latter always has a wider range of applications while the precision is less than the former. Fortunately, some multi-parameter EOSs both possess a high calculation precision and a wide range of applications ${ }^{4,5}$, although their solution methods with unknown multipleparameters are always very difficult and time-consuming. Among the large number of multi-parameter EOSs, the Benedict-Webb-Rubin ${ }^{6-8}$ EOS (B-W-R EOS) and the Martin-Hou EOS (M-H EOS) ${ }^{9-12}$ are very representative and excellent with significant differences in terms of the precision and the range of application. On the one hand, the calculation precision of the two equation in gas-phase state is approximately equivalent and high enough for the practical application while the B-W-R EOS is more precise in liquid-phase state; On the other hand, the M-H EOS has a much broader scope of applications for most kinds of substances, even the strong polar substances such as $\mathrm{H}_{2} \mathrm{O}$ and $\mathrm{NH}_{3}$ and so on, while the B-W-R EOS is mainly used to calculate the properties of hydrocarbons. Moreover, the initial value conditions for the derivation of the unknown characteristic constants in the M-H EOS are more accessible and easy to use.

Although the M-H EOS was originally put forward in the form of an empirical equation, its theoretical formula had been strictly proved ${ }^{13,14}$ by the theory of Hard-particle Perturbation theory ${ }^{15-18}$. Nowadays, the main investigation of the M-H EOS has changed from the theory's exploration to the application of given substances in different cases. First and foremost, especially in refrigeration industry ${ }^{19-21}$, the M-H EOS is widely applied as a specific EOS for a given substance, such as $\mathrm{H}_{2} \mathrm{O}^{22,}{ }^{23}, \mathrm{CO}_{2}{ }^{24}$, natural gas ${ }^{25}$ and so on ${ }^{26}$. Second, the M-H EOS is extended to achieve diversified applications ${ }^{27-32}$, e.g., the crossover multi-parameter $\mathrm{EOS}^{31,32}$. Last but not least, the combination of the M-H EOS with other theories is further developed, which has solved many thorny problems in the past ${ }^{33-36}$.

Although many satisfying researches have been achieved, the improvement of the M-H EOS itself is essentially stagnant for the application in liquid-phase state after the modified M-H EOS put forward by $\mathrm{Hou}^{12}$. In fact, the original M-H EOS is not very proper to the calculation in liquid-phase state ${ }^{9}$, as the improved formula, Hou's modified M-H EOS is also not as satisfactory as desired in term of the calculation precision. In general, most average deviation by Hou's modified M-H EOS is less than $5 \%$ in liquid-phase state, while partial maximum deviations are up to $15 \% \sim 20 \%^{12}$. It is still of great potential to improve the calculation precision of the M-H EOS in liquid-phase state.

In this work, we focus on improving the precision of the M-H EOS in liquid-phase state. First, based on rigorous derivation and a large number of literature data analysis, the M-H EOS is further modified and the novel formula will be put forward by introducing an appropriate revision factor $h$; And then, the novel M-H EOS will be applied to six representative substances to verify the generality of the novel EOS and the improvement of calculation precision in liquid-phase state, all the data calculated by different EOS are listed in the supporting information. At last, the conclusion is drawn. In the appendixes, the unknown characteristic constants in the novel M-H EOS are derived in detail.

\section{THE ESTABLISHMENT OF THE NOVEL M-H EOS}

\section{The basis of arithmetic solution of the Hou's modified M-H EOS}

The M-H EOS was originally proposed as an empirical equation by Martin and Hou in 1955 on the basis of a large number of P-V-T data analysis about many kinds of substances. The initial formula can be expressed as follows ${ }^{9}$ :

$\mathrm{P}=\sum_{i=1}^{5} \frac{f_{i}(T)}{(V-b)^{i}}(1)$

withf $_{\mathrm{i}}(\mathrm{T})=\mathrm{A}_{\mathrm{i}}+\mathrm{B}_{\mathrm{i}} \mathrm{T}+\mathrm{C}_{\mathrm{i}} \mathrm{e}^{-\mathrm{k} \frac{\mathrm{T}}{\mathrm{T}_{\mathrm{c}}}}(2)$

where $k=5.475, A_{i}, B_{i}, C_{i}$, and $b$ are the characteristic constants for a given substance.

Based on the universal physical properties of substances, there are 10 initial value conditions for the EOS, however, the unknown characteristic constants are up to $16^{9}$. Fortunately, not every characteristic constant is of equal importance or necessary, which means those less important characteristic constants can be omitted. Ref. (9) gave the detailed reasons for the simplification of the related unknown characteristic constants and 
the theory foundations of the initial value conditions. In this work, we just exhibit the result of the simplified $f_{i}(T)$ and the initial value conditions of the M-H EOS.

The simplified $f_{i}(T)$ can be expressed as follows ${ }^{9}$ :

$\mathrm{f}_{1}(\mathrm{~T})=\mathrm{B}_{1} \mathrm{~T}(3)$

$\mathrm{f}_{2}(\mathrm{~T})=\mathrm{A}_{2}+\mathrm{B}_{2} \mathrm{~T}+\mathrm{C}_{2} \mathrm{e}^{-5.475 \frac{\mathrm{T}}{\mathrm{T}_{\mathrm{c}}}}(4)$

$\mathrm{f}_{3}(\mathrm{~T})=\mathrm{A}_{3}+\mathrm{B}_{3} \mathrm{~T}+\mathrm{C}_{3} \mathrm{e}^{-5.475 \frac{\mathrm{T}}{\mathrm{T}_{\mathrm{c}}}}(5)$

$\mathrm{f}_{4}(\mathrm{~T})=\mathrm{A}_{4}(6)$

$\mathrm{f}_{5}(\mathrm{~T})=\mathrm{B}_{5} \mathrm{~T}(7)$

The number of the unknown characteristic constants is 10: $A_{1}, A_{2}, B_{2}, C_{2}, A_{3}, B_{3}, C_{3}, A_{4}, B_{5}, b$.

The initial value conditions of the M-H EOS are expressed as follows ${ }^{9}$ :

$\mathrm{P}_{\mathrm{c}}=\mathrm{P}\left(\mathrm{T}_{\mathrm{c}}, \mathrm{V}_{\mathrm{c}}\right)(8)$

$\mathrm{PV}=\mathrm{RT}$ as $\mathrm{P} \rightarrow 0(9)$

$(\mathrm{dP} / \mathrm{dV})_{\mathrm{T}_{\mathrm{c}}}=0(10)$

$\left(\frac{\mathrm{d}^{2} \mathrm{P}}{\mathrm{dV}^{2}}\right)_{\mathrm{T}_{\mathrm{c}}}=0(11)$

$\left(\frac{\mathrm{d}^{3} \mathrm{P}}{\mathrm{dV}^{3}}\right)_{\mathrm{T}_{\mathrm{c}}}=0(12)$

$\left(\frac{\mathrm{d}^{4} \mathrm{P}}{\mathrm{dV}^{4}}\right)_{\mathrm{T}_{\mathrm{c}}}=0(13)$

$\left[\left(\frac{\mathrm{dZ}}{\mathrm{dP}_{\mathrm{r}}}\right)_{\mathrm{T}_{\mathrm{r}}}\right]_{\mathrm{P}_{\mathrm{r}}=0}=-\left(1-\mathrm{Z}_{\mathrm{c}}\right) \quad$ at $\quad \mathrm{T}^{\prime} \cong 0.8 \mathrm{~T}_{\mathrm{c}}(14)$

$\left[\left(\frac{\mathrm{dZ}}{\mathrm{dP}_{\mathrm{r}}}\right)_{\mathrm{T}_{\mathrm{r}}}\right]_{\mathrm{P}_{\mathrm{r}}=0}=0 \quad$ at $\quad$ Boyle - Point Temperature $\mathrm{T}_{\mathrm{B}}(15)$

$(\mathrm{dP} / \mathrm{dT})_{\mathrm{V}}=\mathrm{m}=-\mathrm{M} \frac{\mathrm{P}_{\mathrm{c}}}{\mathrm{T}_{\mathrm{c}}} \quad$ at $\quad \mathrm{V}=\mathrm{V}_{\mathrm{c}}(16)$

$\left(\frac{\mathrm{d}^{2} \mathrm{P}}{\mathrm{dT}^{2}}\right)_{\mathrm{V}}=0 \quad$ at $\quad \mathrm{V}=\mathrm{V}_{\mathrm{c}}(17)$

Here, the number of the initial value conditions of the M-H EOS is also 10.

Although the arithmetic solutions of the unknown characteristic constants can be obtained by using the initial value conditions above, there still is a major defect that the precision calculated by the M-H EOS in liquid-phase state is too low in practical applications ${ }^{9,12}$. In fact, the original EOS was mostly suitable for the calculation in gas-phase state.

After the original M-H EOS was put forward, Martin ${ }^{10,11}$ and Hou ${ }^{12}$ independently revised the original M-H EOS in order to extend application range to liquid-phase state. Among them, the new formula modified by Hou is more prominent ${ }^{12}$. According to the constraint condition of gas-liquid equilibrium, Hou introduced a new initial value condition and a new characteristic constant $B_{4}$ into the original M-H EOS. Hou's modified M-H EOS expands the range of applications to liquid-phase state ${ }^{12}$.

The formula is similar as the original M-H EOS except that $f_{4}(T)$ has a change which adds a new characteristic constant $\mathrm{B}_{4}$. The new $\mathrm{f}_{4}(\mathrm{~T})$ is expressed as follows ${ }^{12}$ : 


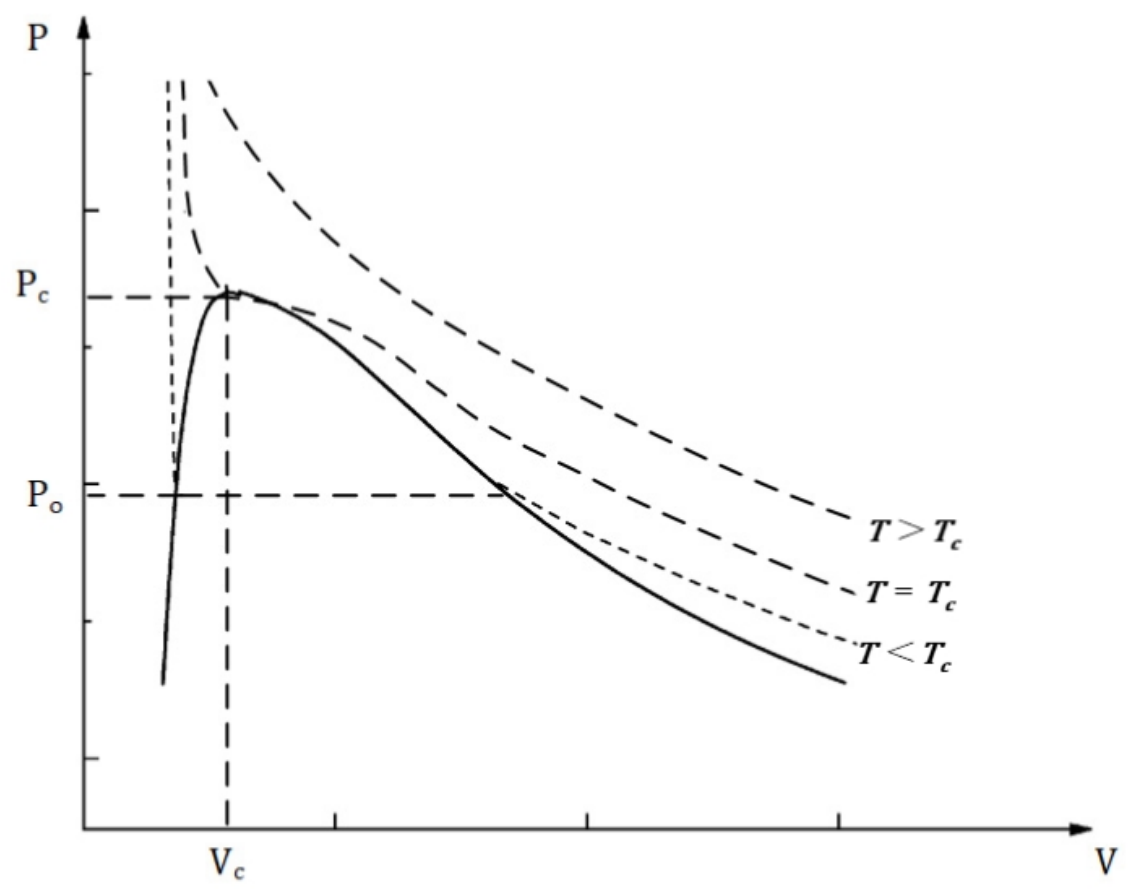

$\mathrm{f}_{4}(\mathrm{~T})=\mathrm{A}_{4}+\mathrm{B}_{4} \mathrm{~T}(18)$

Figure 1 Pressure-Volume diagram ${ }^{12}$

Due to the introduction of $B_{4}$, a new initial value condition should be introduced. Hou proposed a new initial value condition possessing a universal significance. Based on the thermodynamic equilibrium that the Gibbs molar free enthalpy of pure substances is equal at vapor-liquid equilibrium under a constant temperature and pressure, the new initial value condition finally can be deduced as $^{12}$ :

$\int_{\mathrm{V}_{\mathrm{l}}}^{\mathrm{V}_{\mathrm{v}}} \mathrm{PdV}=\mathrm{P}_{\mathrm{O}}\left(\mathrm{V}_{\mathrm{v}}-\mathrm{V}_{\mathrm{l}}\right)(19)$

\section{The establishment of the novel M-H EOS}

After rigorous experiment calculations and a large number of data analysis about substances in liquid-phase state and on the consideration of the simplicity of calculation, the novel M-H EOS is put forward as follows:

$\mathrm{P}=\sum_{\mathrm{i}=1}^{5} \frac{\mathrm{f}_{\mathrm{i}}(\mathrm{T})}{[(\mathrm{V}-\mathrm{b}) \mathrm{h}]^{\mathrm{i}}}(20)$

whereh $=\left[\frac{\ln \left(1+\mathrm{Z}_{\mathrm{c}}\right)}{\mathrm{Z}_{\mathrm{c}}}\right]^{\mathrm{Z}_{\mathrm{c}}}(21)$

The revision factor $h$, which is the function of $Z_{\mathrm{c}}$, is mainly proposed to correct the molar volume in liquid-phase state. The structure of $h$ is mainly established on the consideration that the derivation of the unknown characteristic constants is closely related to the property of critical point, which can be appropriately conveyed by a function of $Z_{\mathrm{c}}$.

After analyzing the solving method of unknown characteristic constants in Hou' M-H EOS and the novel M-H EOS, we obtain the solving method of the unknown characteristic constants in the novel M-H EOS, which has a great improvement compared with Hou' method. Refer to the appendixes for the details.

DISCUSSION ABOUT THE VERIFICATION AND APPLICATION OF THE NOVEL M-H EOS

The analysis of the derivation about the unknown c haracteristic constants 
The solving details of the unknown characteristic constants in the novel M-H EOS are presented in the Appendix I and Appendix II.

Through the analysis of the detailed derivation of the novel EOS amended by $h$, all the initial value conditions and the simplified $f_{i}(T)$ of the novel M-H EOS are the same as those in Hou's modified M-H EOS ${ }^{12}$. Meanwhile, $h$ is a constant for a given substance, it avoids the difficulty of the discussion about variables. However, after analyzing the derivation process of the novel M-H EOS, we found a defect that over-revision about some characteristic constants maybe exist when the state is beyond liquid-phase state because the space between molecules will be obviously affected by temperature and pressure and the influence may be amplified by $h$ because the solutions of all the characteristic constants are affected by $h$ in some degree, although $h$ is mainly designed to revise the molar volume in liquid-phase state.

In the novel M-H EOS, only a minimum amount of information is necessary to characterize a given substance. In this work, the novel M-H EOS has been applied to six representative substances: argon, methane, nitrogen, propane, benzene and water to verify its generality and calculation precision in liquid-phase state. The physical constants of these substances are listed in Table 1 except $\frac{\mathrm{R}=82.055\left(\mathrm{~atm} . \mathrm{cm}^{3}\right)}{(\mathrm{K} . \mathrm{mol})}$ and its calculated characteristic constants are listed in Table2 ${ }^{37-40}$.

Table 1 The physical constants of given substances

\begin{tabular}{llllllllll}
\hline Constant & $\omega$ & $\mathrm{b}$ & $Z_{\mathbf{c}}$ & $V_{\mathbf{c}}$ & $P_{\mathbf{c}}$ & $T_{\mathbf{c}}$ & $T_{\mathbf{B}}$ & $T^{\prime}$ & $\mathrm{h}$ \\
\hline $\mathbf{U n i t}$ & $/$ & $\mathbf{c m}^{\mathbf{3}} / \mathbf{m o l}$ & $/$ & $\mathbf{c m}^{\mathbf{3}} / \mathbf{m o l}$ & $\mathbf{a t m}$ & $\mathbf{K}$ & $\mathbf{K}$ & $\mathbf{K}$ & $/$ \\
$\mathbf{A}_{\mathbf{r}}$ & -0.002 & 16.432 & 0.291 & 74.48 & 48.34 & 150.86 & 382.18 & 116.16 & 0.96276 \\
$\mathbf{C H}_{\mathbf{4}}$ & 0.011 & 20.811 & 0.286 & 98.83 & 45.80 & 190.55 & 470.54 & 147.30 & 0.96394 \\
$\mathbf{N}_{\mathbf{2}}$ & 0.037 & 19.958 & 0.289 & 92.14 & 33.52 & 126.25 & 326.49 & 99.74 & 0.96323 \\
$\mathbf{C}_{\mathbf{3}} \mathbf{H}_{\mathbf{8}}$ & 0.152 & 38.084 & 0.276 & 200.00 & 41.92 & 369.83 & 847.44 & 296.08 & 0.96626 \\
$\mathbf{C}_{\mathbf{6}} \mathbf{H}_{\mathbf{6}}$ & 0.210 & 44.651 & 0.268 & 256.00 & 48.31 & 562.05 & 1211.05 & 453.00 & 0.96807 \\
$\mathbf{H}_{\mathbf{2}} \mathbf{O}$ & 0.344 & 5.396 & 0.229 & 55.950 & 217.75 & 647.14 & 1358.62 & 538.62 & 0.97627 \\
\hline
\end{tabular}

Table 2 The calculated characteristic constants of given substances

\begin{tabular}{llll}
\hline Constant & $A_{\mathbf{2}}$ & $B_{\mathbf{2}}$ & $C_{\mathbf{2}}$ \\
\hline $\mathbf{A}_{\mathbf{r}}$ & -1792898.66 & 3441.51 & 872181.85 \\
$\mathbf{C H}_{\mathbf{4}}$ & -3084719.67 & 4968.95 & 211562.88 \\
$\mathbf{N}_{\mathbf{2}}$ & -1701726.30 & 3692.77 & -10298588.83 \\
$\mathbf{C}_{\mathbf{3}} \mathbf{H}_{\mathbf{8}}$ & -13129207.68 & 12574.69 & -78043586.37 \\
$\mathbf{C}_{\mathbf{6}} \mathbf{H}_{\mathbf{6}}$ & -27992807.70 & 19682.00 & -173091564.06 \\
$\mathbf{H}_{\mathbf{2}} \mathbf{O}$ & -8067873.54 & 5517.51 & -164164167.15 \\
$\mathbf{C o n s t a n t}$ & $A_{\mathbf{3}}$ & $B_{\mathbf{3}}$ & $C_{\mathbf{3}}$ \\
$\mathbf{A}_{\mathbf{r}}$ & 81961752.04 & -108838.45 & -48738662.73 \\
$\mathbf{C H}_{\mathbf{4}}$ & 195188464.79 & -255914.35 & -15910815.83 \\
$\mathbf{N}_{\mathbf{2}}$ & 94850730.88 & -150115.81 & 716037146.24 \\
$\mathbf{C}_{\mathbf{3}} \mathbf{H}_{\mathbf{8}}$ & 1785767971.59 & -1501172.10 & 12209442501.92 \\
$\mathbf{C}_{\mathbf{6}} \mathbf{H}_{\mathbf{6}}$ & 5086922374.24 & -3281019.89 & 35414754826.18 \\
$\mathbf{H}_{\mathbf{2}} \mathbf{O}$ & 429538013.90 & -324584.19 & 8102254816.01 \\
$\mathbf{C o n s t a n t}$ & $A_{\mathbf{4}}$ & $B_{\mathbf{4}}$ & $B_{\mathbf{5}}$ \\
$\mathbf{A}_{\mathbf{r}}$ & -1451145885.12 & -1568975.71 & 116294369.50 \\
$\mathbf{C H}_{\mathbf{4}}$ & -4521170115.59 & -2675888.63 & 365167238.20 \\
$\mathbf{N}_{\mathbf{2}}$ & -2636587322.41 & 1568766.87 & 239858253.73 \\
$\mathbf{C}_{\mathbf{3}} \mathbf{H}_{\mathbf{8}}$ & -108027874348.69 & 38740752.52 & 7451592484.28 \\
$\mathbf{C}_{\mathbf{6}} \mathbf{H}_{\mathbf{6}}$ & -395623942694.11 & 121873139.75 & 22580920915.78
\end{tabular}




\begin{tabular}{llll}
\hline Constant & $A_{\mathbf{2}}$ & $B_{\mathbf{2}}$ & $C_{\mathbf{2}}$ \\
\hline $\mathbf{H}_{\mathbf{2}} \mathbf{O}$ & -10866343662.24 & 7209626.01 & 93881687.29 \\
\hline
\end{tabular}

By substituting these parameters in the above Table 2 into the novel M-H EOS, the new M-H EOS of a given substance will be achieved. The calculation results and their corresponding deviations of the above six substances have been listed in the supporting information ${ }^{37-40}$.

\section{The comparison between the novel M-H EOS and other EOSs.}

The result of molar volume can be calculated when pressure is given. In order to avoid imaginary root, the corresponding values of molar volume are calculated by dichotomy using Matlab. In this work, we mainly focus on the volume calculated in liquid-phase state because the precision of volume calculated in gas-phase state is high enough by using the previous M-H EOS ${ }^{9,12}$.

Besides Hou's modified M-H EOS, we select two general EOS as comparisons. Among the large number of general EOSs, the Soave-Redlich-Kwong EOS (S-R-K EOS) and the Peng-Robinson EOS (P-R EOS) are most representative and specially used for the comparison ${ }^{41-43}$. The S-R-K EOS is expressed as follows:

$P=\frac{\mathrm{RT}}{\mathrm{V}-\delta}-\frac{\mathrm{a}(\mathrm{T})}{\mathrm{V}(\mathrm{V}+\delta)}$

where

$$
\begin{aligned}
& \mathrm{a}(\mathrm{T})=0.42748 \frac{\mathrm{R}^{2} \mathrm{~T}_{\mathrm{c}}^{2}}{\mathrm{P}_{\mathrm{c}}}\left[1+\left(0.48+1.534 \omega-0.176 \omega^{2}\right)\left(1-\mathrm{T}_{\mathrm{r}}^{0.5}\right)\right]^{2} \\
& \delta=0.08664 \frac{\mathrm{RT}_{\mathrm{c}}}{\mathrm{P}_{\mathrm{c}}}(24)
\end{aligned}
$$

The P-R EOS is expressed as follows:

$\mathrm{P}=\frac{\mathrm{RT}}{\mathrm{V}-\delta}-\frac{\mathrm{a}(\mathrm{T})}{\mathrm{V}(\mathrm{V}+\delta)+\delta(V-\delta)}$

where

$$
\begin{aligned}
& \mathrm{a}(\mathrm{T})=0.45724 \frac{\mathrm{R}^{2} \mathrm{~T}_{\mathrm{c}}^{2}}{\mathrm{P}_{\mathrm{c}}}\left[1+\left(0.37464+1.54226 \omega-0.26992 \omega^{2}\right)\left(1-\mathrm{T}_{\mathrm{r}}^{0.5}\right)\right]^{2}(26) \\
& \delta=0.07780 \frac{\mathrm{RT}_{\mathrm{c}}}{\mathrm{P}_{\mathrm{c}}}(27)
\end{aligned}
$$

The deviation of volume between the calculated data $\left(V_{C a l}\right)$ and the experiment data in literatures $\left(V_{\operatorname{Exp}}\right.$ ) is defined as:

Dev. $=\left|\frac{\mathrm{V}_{\text {Exp }}-\mathrm{V}_{\text {cal }}}{\mathrm{V}_{\operatorname{Exp}}}\right| \times 100 \%$

Table 3 The maximum and average deviation in liquid-phase state

\begin{tabular}{lllllllll}
\hline *Deviation (\%) & EOS & $\mathbf{A}_{\mathbf{r}}$ & $\mathbf{C H}_{\mathbf{4}}$ & $\mathbf{N}_{\mathbf{2}}$ & $\mathbf{C}_{\mathbf{3}} \mathbf{H}_{\mathbf{8}}$ & $\mathbf{C}_{\mathbf{6}} \mathbf{H}_{\mathbf{6}}$ & $\mathbf{H}_{\mathbf{2}} \mathbf{O}$ & Average value \\
\hline \multirow{2}{*}{ The maximum deviation } & The S-R-K EOS & 3.31 & 4.67 & 5.11 & 10.59 & 14.89 & 43.99 & $* * 13.76$ \\
& The P-R EOS & 14.86 & 11.10 & 9.14 & 5.71 & 3.06 & 28.14 & $* * 12.00$ \\
& Hou's M-H EOS & 6.42 & 6.27 & 6.61 & 4.13 & 4.17 & 7.19 & 5.80 \\
& The Novel EOS & 4.00 & 3.70 & 2.97 & 2.63 & 2.43 & 5.29 & 3.50 \\
The average deviation & The S-R-K EOS & 2.05 & 2.83 & 3.06 & 8.64 & 12.03 & 41.82 & $* * 11.74$ \\
& The P-R EOS & 12.17 & 8.74 & 5.80 & 3.68 & 2.04 & 25.62 & $* * 9.68$ \\
& Hou's M-H EOS & 2.89 & 3.49 & 3.62 & 1.58 & 1.31 & 2.18 & 2.51 \\
& The Novel EOS & 1.83 & 1.47 & 1.17 & 0.95 & 0.81 & 1.50 & 1.29 \\
\hline
\end{tabular}

\footnotetext{
* The deviation is expressed in absolute value.
} 
${ }^{*}$ The average values are non-serviceable because the data of water by the S-R-K EOS and the P-R EOS are of no practical significance.

The comparison with Hou's modified M-H EOS:Among the selected substances, the average value of the maximum deviation calculated by Hou's modified M-H EOS is $5.80 \%$ while it is $3.50 \%$ by the novel M-H EOS. At the same time, the average deviation from the novel EOS is much less than those from Hou's equation, as shown in Table 3 , the average value of average deviation is $2.51 \%$ by Hou's M-H EOS while it is $1.29 \%$ by the novel M-H EOS. Therefore, the conclusion can be drawn that the novel M-H EOS can obviously reduce the deviation and improve the calculation precision in liquid-phase state. However, the degree of improvement about the strong polar substances is smaller compared with other substances. It may be attributed to the reason that intermolecular forces between strong polar moles are stronger and more complex in liquid-phase state while the single revision factor $h$ could not appropriately revise the variation tendency.

The comparisonwith other general EOSs :The data about molar volume calculated by the S-R-K EOS and the P-R EOS are listed in Table 3 and the supporting information ${ }^{41-43}$. It is indicated that with the increase of eccentric factor $(\omega)$, the deviations calculated by the S-R-K EOS increase more rapidly than those by the P-R EOS in liquid-phase state, which means the S-R-K EOS is more suitable for the condition that the eccentric factor is small. The P-R EOS is an improved formula of the S-R-K EOS, it is of a broader scope of application with the increase of $\omega$ while it's precision is not satisfying when $\omega$ is too small. Moreover, the S-R-K EOS and the P-R EOS are both not suitable for strong polar substances with respect to the maximum and average deviation both in excess of 20\%; At the same time, the variation intervals of deviation by the two general EOS are both too large, which means the calculation results are instable for application: the maximum deviations change from $3.31 \%$ to $14.89 \%$ by the S-R-K EOS and $3.06 \%$ to $14.86 \%$ by the P-R EOS for the selected five substances except water, the average deviations change from $2.05 \%$ to $12.03 \%$ by the S-R-K EOS and $2.04 \%$ to $12.17 \%$ by the P-R EOS. The general EOSs should always be further revised for the cases in liquid-phase state if they wanted be used in the practical applications.

The novel M-H EOS has more advantages no matter the precision or the stability of calculation: The variation range of the maximum deviations about the selected five substances except water change from $2.43 \%$ to $4.00 \%$, and the variation range of the average deviations are within the scope of $0.81 \%$ to $1.83 \%$.

\section{CONCLUSION}

Because of the application defect for the original and Hou's modified M-H EOS in the liquid phase, a novel M-H EOS is put forward. A new revision factor $h$ is introduced into the EOS to reduce the deviation of molar volume calculated in liquid-phase state. According to the new detailed derivation in the appendixes, only a few number of physical properties are needed to characterize a given substance. Last, the novel M-H EOS has been applied to six representative substances to verify its generality and calculation precision in liquid-phase state. According to the analysis of the data by the above EOSs, the average value of the maximum deviations for the selected six representative substances reduces from $5.80 \%$ by Hou's modified M-H EOS to $3.50 \%$ by the novel M-H EOS and the average value of the average deviations reduces from $2.51 \%$ to $1.29 \%$. At the same time, this novel M-H EOS exhibit higher calculation precision compared to some other general EOSs in the liquid phase. Therefore, the conclusion can be drawn that the precision is obviously improved in liquid-phase by applying the novel M-H EOS.

Another progress is made in the solving process of $B_{4}$. We design a new calculation program instead of the trial and error method in Hou' modified M-H EOS. It greatly simplify the process of calculation and improve the computational efficiency. Refer to Appendix I for details.

\section{ACKNOWLEDGEMENTS}

We sincerely appreciate the financial support from the National Natural Science Foundation of China (Grant number 91641121).

\section{Supporting Information}


The supplemented data of the solution by the novel M-H EOS, Hou's modified M-H EOS, the S-R-K EOS and the P-R EOS.

\section{Notes}

$\mathrm{Ai}, \mathrm{Bi}, \mathrm{Ci},-$ Characteristic constants

G-Gibbs molar free enthalpy

A-Helmholtz molar free energy

$$
\mathrm{P} \text {-Pressure, atm }
$$

$\frac{\mathrm{R} \text {-Gas constant, } 82.055\left(\mathrm{~atm} \cdot \mathrm{cm}^{3}\right)}{(\mathrm{K} . \mathrm{mol})}$

$\mathrm{T}$-Absolute temperature, $\mathrm{K}$

$\mathrm{T}_{\mathrm{B}}-$ Boyle temperature, $\mathrm{K}$

$$
\text { V-Molar volume, } \frac{\mathrm{cm}^{3}}{\mathrm{~mol}}
$$

Z-Compressibility factor,PV/RT

$$
\text { b-Characteristic constants, } \frac{\mathrm{cm}^{3}}{\mathrm{~mol}}
$$

$\omega$-Characteristic constants, Acentric factor

$\mathrm{h}-$ Characteristic constants, revision factor

$\mathrm{m}$-The slope of critical molar volume line in $\mathrm{P} \sim \mathrm{T}$ chart, at $\mathrm{V}=\mathrm{V}_{\mathrm{c}}$

\section{Subscript:}

$$
\begin{gathered}
\text { c-Critical value } \\
\text { l-Saturated liquid phase } \\
\text { v-Saturated gas phase } \\
\text { o-Vapor pressure data point, e.g. } \mathrm{T}_{\mathrm{o}}, \mathrm{P}_{\mathrm{o}} \\
\text { r-Reduced property, e.g. } \mathrm{T}_{\mathrm{r}}=\frac{\mathrm{T}}{\mathrm{T}_{\mathrm{c}}, \mathrm{P}_{\mathrm{r}}=\frac{\mathrm{P}}{\mathrm{P}_{\mathrm{c}}}} .
\end{gathered}
$$

\section{References}


1. Zhu, Z. Y.; Zhang, F. K.; Xu, C. Development of the Martin-Hou (M-H) Equation of State Application. Shanghai Chemical Industry.2011; 36: 12-15.

2. Han, X. H.; Chen, G. M.; Wang, Q.; et al. A Review on Equation of State. Natural Gas Chemical Industry . 2005 ; 30: 52-61.

3. Eliezer, S.; Hora, H.; Ghatak, A. Fundamentals of Equations of State.World Scientific . 2002 .

4. Jacobsen, R. T.; Penoncello, S. G.; Lemmon, E. W.; et al. 18 Multi-parameter Equations of State. Experimental Thermodynamics . 2000 ; 5: 849-881.

5. Span, R.; Multi-parameter Equations of State. Springer Berlin Heidelberg . 2000 ; 4: 113-174.

6. Benedict, M.; Webb, G. B.; Rubin, L. C. An Empirical Equation for Thermodynamic Properties of Light Hydrocarbons and Their Mixtures 2. Methane, Ethane, Propane and n-Butane. The Journal of Chemical Physics . 1942 ; 10: 747-758.

7. Carnahan, N. F. Equation of State for Non-attracting Rigid Spheres. The Journal of Chemical Physics . 1969 ; 5: 635-636.

8. Mansoori, G. A.; Carnahan, N. F.; Starling, K. E.; Leland, T. W. Equilibrium Thermodynamic Properties of the Mixture of Hard Spheres. The Journal of Chemical Physics . 1971 ; 54: 1523-1525.

9. Martin, J. J.; Hou, Y. C. Development of An Equation of State for Gases. Aiche Journal . 1955 ; 1 : $142-151$.

10. Martin, J. J.; Rajendra, M. K.; Noel, D. N. An Improved Equation of State for Gases. Aiche Journal . 1959 ; 5: 159-160.

11. Martin, J. J.; Thomas, G. S. Development of High Precision Equations of State for Wide Ranges of Density Utilizing A Minimum of Input Information. Aiche Journal . 1974 ; 70: 79-87.

12. Hou, Y. C.; Zhang, B. J.; Tang, H. Q. Extension of Martin-Hou Equation of State into Liquid Region. Chinese Journal of Chemical Engineering . 1983 ; 2: 1-11.

13. Hou, Y. C.; Zhang, B. J. Proof and Explanation of Statistical Mechanics about Martin-Hou Equation of State etc. Journal of Chemical Industry and Engineering . 1989 ; 40: 263-270.

14. Zhang, B. J.; Hou, Y. C. Derivation of Martin-Hou Equation of State from Hard-particle Perturbation Theory. Chinese Journal of Chemical Engineering . 2000 ; 16: 49-56.

15. Hirschfelder, J. O.; Curtiss, C. F.; Bird, R. B. Molecular Theory of Gases and Liquids. John Wiley $\&$ Sons . $1954 ; 5$ : 1-436.

16. Barboy, B.; Gelbart, W. M.; Series Representation of the Equation of State for Hard Particle Fluids. The Journal of Chemical Physics . 1979 ; 71: 3053-3062.

17. Germain, P.; Amokrane, S.; Validity of the Perturbation Theory for Hard Particle Systems with Veryshort-range Attraction. Physical Review E . 2002 ; 65: 031109-031109.

18. Yuko, I.; Akira, Y.; Akiyama Ryo, A. Perturbation Theory of Large-Particle Diffusion. J. Phys. Soc. Jpn. 2012 ; 81: 114603-114613.

19. Zhong, Q.; Dong, X.; Zhao, Y.; et al. A Simple Generalized Equation for Compressed Liquid Isochoric Heat Capacity of Pure and Mixture Refrigerants. Fluid Phase Equilibria . 2019 ; 490: 33-38.

20. Monte, F. D. Calculation of Thermodynamic Properties of R407C and R410A by the Martin-Hou Equation of State - Part I: Theoretical Development. International Journal of Refrigeration .2002 ; 25: 306-313.

21. Monte, F. D. Calculation of Thermodynamic Properties of R407C and R410A by the Martin-Hou Equation of State - part II: Technical Interpretation. International Journal of Refrigeration .2002 ; 25: 314-329.

22. Du, A. P.; Chen, X. Z.; Hou, Y. J. Development of Martin-Hou Equation of State for Water. Chemical Engineering (China) .2002; 30: 50-53.

23. Tie, l. R.; Xue, W.; Bao, D. L. Establish the Improved Water Vapor State Equation Based on M-H-th. Energy for Metallurgical Industry . 2016 ; 35: 26-29.

24. Leal, D. S.; Marcelo, E.; Costa, G. M. N.; et al. Prediction of Thermodynamic Properties of $\mathrm{CO}_{2}$ by Cubic and Multi-parameter Equations of State for Fluid Dynamics Applications.Journal of Chemical E) Engineering Data . 2019 ; 64: 1746-1759.

25. Papari, M. M.; Boushehri, A.; Rostami, A. A.; et al. Common Intersection Points of Bulk Modulus for 
Liquefied Natural Gas (LNG) Mixtures. Journal of the Chinese Chemical Society .2005 ; 52: 209-213.

26. Mirosław, C. Z.; Karel, A.; Wichterle, I.; Jacquemin, J.; Polishuk, I. High-pressure Phase Equilibrium in the \{Carbon Dioxide (1) +1 -Chloropropane (2)\} Binary System. The Journal of Chemical Thermodynamics . 2015 ; 91: 165-171.

27. Martín, á.; Bermejo, M. D.; Mato, F. A. ; et al. Teaching Advanced Equations of State in Applied Thermodynamics Courses Using Open Source Programs. Education for Chemical Engineers . 2011 ; 6: 114-121.

28. Nan, Y. Q.; Hao, L. S.; Hou, Y. C.; Yu, Q. S. The Associating Martin-Hou (AMH) Equation of State. III. Extension of the AMH EOS to Systems Containing Any Number of Alcohols and Inert Compounds.Fluid Phase Equilibrium . 2001 ; 191: 155-175.

29. Grigoriev, B.; Alexandrov, I.; Gerasimov, A. Application of Multi-parameter Fundamental Equations of State to Predict the Thermo-dynamic Properties and Phase Equilibria of Technological Oil Fractions. Fuel . $2018 ; 215$ : 80-89.

30. Nan, Y. Q.; Hou, Y. C.; Yu, Q. The Associating M-H Equation of State.Acta Physico-Chimica Sinica. 1997 ; 13: 725-731.

31. Belyakov, M. Y.; Kulikov, V. D.; Muratov, A. R.; et al. Crossover Equation of State of a MultiComponent Fluid Mixture in The Vicinity of Liquid-Vapor Critical Points. Chemical Physics .2018; 513: 149-155.

32. Yang, F.; Liu, Q.; Duan, Y.; et al. Crossover Multi-parameter Equation of State: General Procedure and Demonstration with Carbon Dioxide.Fluid Phase Equilibria . 2019 ; 494: 161-171.

33. Nan, Y. Q.; Hao, L. S. The Applications of Association Martin-Hou Equation of State to Carboxylic Acid + Hydrocarbon systems. Journal of Natural Science of Hunan Normal University .2003 ; 26 : 58-65.

34. Zeng, W. P.; Long, Q.; Gu, B.; Hu, H.; Zhang, C. L. Fast Calculation of Thermo-dynamic and Transport Properties of $\mathrm{CO}_{2}$ in Sub-critical Pressure Region - Based on the Martin-Hou Equation of State. Cryogenics and Superconductivity. 2008 ; 36: 50-55.

35. Ekundayo, J. M.; Rezaee, R. Effect of Equation of States on High-Pressure Volumetric Measurements of Methane-Coal Sorption Isotherms-Part 1: Volumes of Free Space and Methane Adsorption Isotherms. Energy Es Fuels . 2019 ; 33: 1029-1036.

36. Hao, L. S.; Nan, Y. Q. Applications of Associating Martin-Hou Equation of State to Vapor-Liquid Equilibria in the Critical Region or the Near-Critical Region. Industrial \& Engineering Chemistry Research . 2007 ; 46: 990-996.

37. Poling, B. E.; Prausnitz, J. M.; O'Connell, J. P. The Properties of Gases and Liquids. McGraw-Hill . 2001 .

38. Daubert, T. E.; Danner, R. P. Data compilation tables of properties of pure compounds. American Institute of Chemical Engineers .1984.

39. Theodore, L.; Dupont, R. R.; Ganesan, K. Unit Operations in Environmental Engineering. Appendix C: Steam Tables. Unit Operations in Environmental Engineering. 2017 ; 10: 55-659.

40. Vargaftik, N. B. Tables on the Thermophysical Properties of Liquids and Gases. 2nd Edition. John Wiley $\&$ Sons, Inc. 1975 .

41. Starling, K. Fluid Thermodynamic Properties for Light Petroleum Systems. JOUR . 1973.

42. Serna, S. Numerical Simulation of Relativistic Flows Described by a General Equation of State. Springer Berlin Heidelberg, 2008 .

43. Wesseling, P.; Heul, D. A Unified Method for Compressible and Incompressible Flows with General Equation of State. Springer US,2001 .

\section{APPENDIX I}

THE SOLVING PROCESS OF THE UNKOWN CHARACTERISTIC CONSTANTS IN THE NOVEL M-H EOS

The solution of $f_{i}\left(T_{c}\right)$ 
Based on the initial value condition of Eq. (9), the solutions of $f_{1}(T)$ can be deduced as follows:

$\mathrm{f}_{1}(\mathrm{~T})=\mathrm{RT}(\mathrm{A} 1)$

Based on the initial value conditions of Eqs. (8), (10), (11) and (13), the solutions of other $f_{i}\left(T_{c}\right)$ can be deduced as follows:

$\mathrm{f}_{2}\left(\mathrm{~T}_{\mathrm{c}}\right)=9 \mathrm{P}_{\mathrm{c}}\left[\left(\mathrm{V}_{\mathrm{c}}-\mathrm{b}\right) \mathrm{h}\right]^{2}-3.8 \mathrm{RT} \mathrm{T}_{\mathrm{c}}\left(\mathrm{V}_{\mathrm{c}}-\mathrm{b}\right) \mathrm{h}(\mathrm{A} 2)$

$\mathrm{f}_{3}\left(\mathrm{~T}_{\mathrm{c}}\right)=5.4 \mathrm{RT}_{\mathrm{c}}\left[\left(\mathrm{V}_{\mathrm{c}}-\mathrm{b}\right) \mathrm{h}\right]^{2}-17 \mathrm{P}_{\mathrm{c}}\left[\left(\mathrm{V}_{\mathrm{c}}-\mathrm{b}\right) \mathrm{h}\right]^{3}(\mathrm{~A} 3)$

$\mathrm{f}_{4}\left(\mathrm{~T}_{\mathrm{c}}\right)=12 \mathrm{P}_{\mathrm{c}}\left[\left(\mathrm{V}_{\mathrm{c}}-\mathrm{b}\right) \mathrm{h}\right]^{4}-3.4 \mathrm{RT}_{\mathrm{c}}\left[\left(\mathrm{V}_{\mathrm{c}}-\mathrm{b}\right) \mathrm{h}\right]^{3}(\mathrm{~A} 4)$

$\mathrm{f}_{5}\left(\mathrm{~T}_{\mathrm{c}}\right)=0.8 \mathrm{RT}_{\mathrm{c}}\left[\left(\mathrm{V}_{\mathrm{c}}-\mathrm{b}\right) \mathrm{h}\right]^{4}-3 \mathrm{P}_{\mathrm{c}}\left[\left(\mathrm{V}_{\mathrm{c}}-\mathrm{b}\right) \mathrm{h}\right]^{5}(\mathrm{~A} 5)$

\section{The solution of $b$}

By substituting the solutions about $f_{i}\left(T_{c}\right)$ of Eqs. (A1) - (A5) into Eq. (20) at the critical point, $b$ can be solved based on Eq. (12) as the following equation:

$\mathrm{b}=\mathrm{V}_{\mathrm{c}}-\frac{\mathrm{RT}_{\mathrm{c}}}{5 \mathrm{P}_{\mathrm{c}} \mathrm{h}}(\mathrm{A} 6)$

It also can be expressed in the form of the critical compression factor:

$\mathrm{b}=\mathrm{V}_{\mathrm{c}}-\frac{\mathrm{RV}_{\mathrm{c}}}{5 \mathrm{Z}_{\mathrm{c}} \mathrm{h}}(\mathrm{A} 7)$

Similar to the treatment in the original M-H EOS, the coefficient is introduced into Eq. $(\mathrm{A} 7)^{9}$. In order to verify whether the new coefficient $\beta$ was valid, a large number of calculations have been carried out rigorously and the final data presented in the support information have verified its feasibility. The new formula of $b$ is expressed as follows:

$\mathrm{b}=\mathrm{V}_{\mathrm{c}}-\frac{\beta V_{c}}{15 Z_{c} h}(\mathrm{~A} 8)$

$\beta$ is a constant for a given substance that depends upon $Z_{\mathrm{c}}$, the value of $\beta$ is between 3.0 and $4.0^{9}$. Figure A1 shows the relationship between $\beta$ and $\beta / Z_{\mathrm{c}}$, it also can be expressed as the following formula:

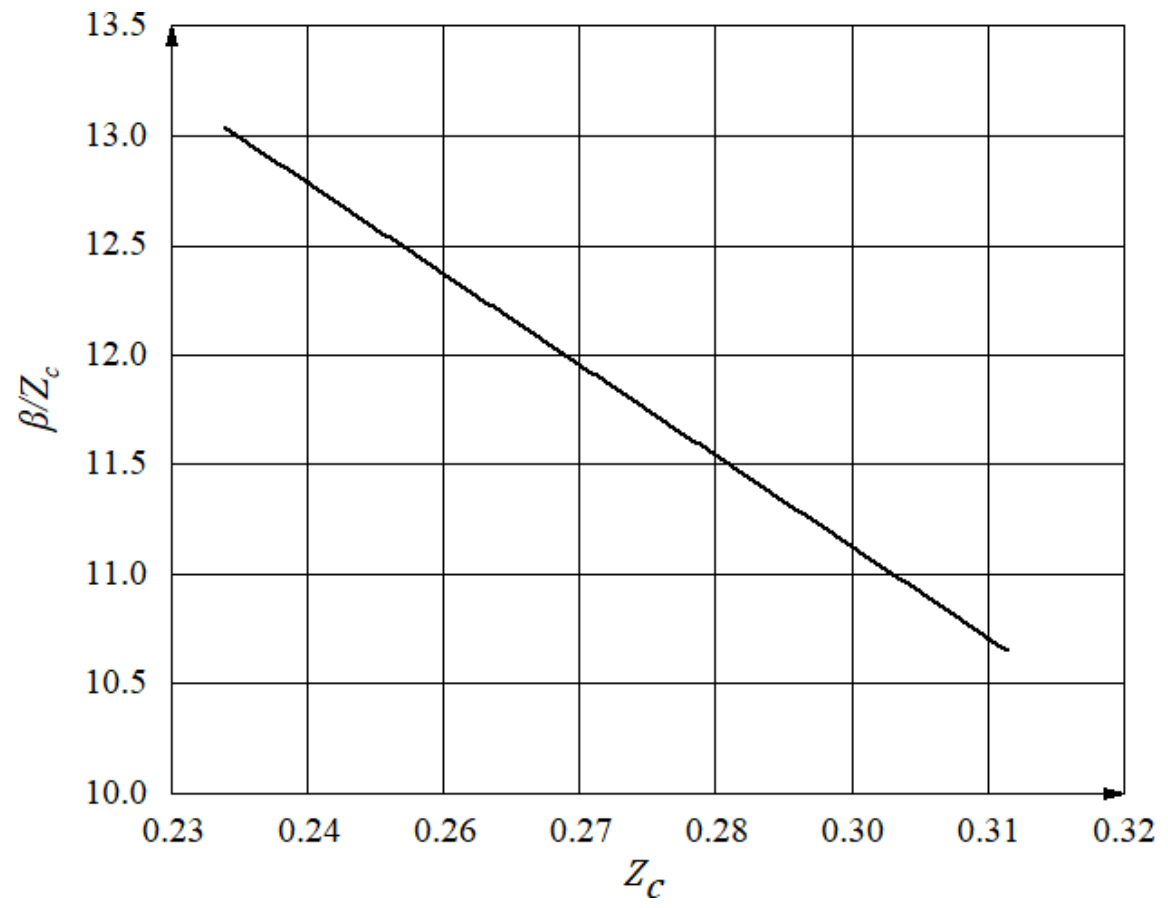




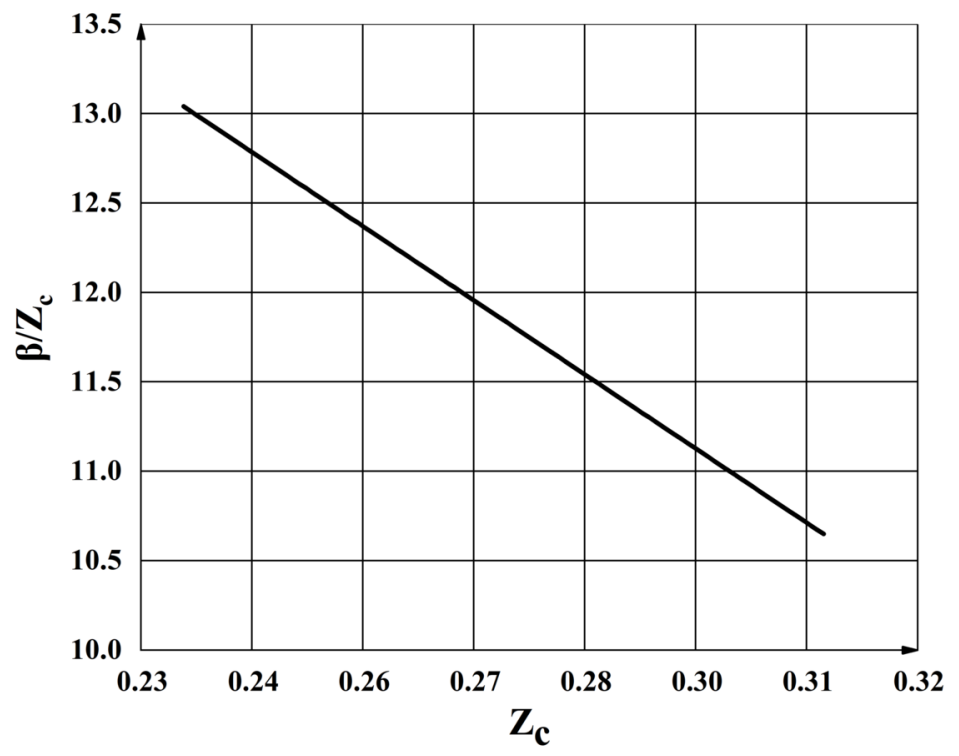

$\beta=-31.883 Z_{c}^{2}+20.533 Z_{c}(\mathrm{~A} 9)$

Figure A1Relation schema between $\beta / Z_{c}$ and $Z_{c}{ }^{12}$

The solution of $B_{5}, C_{2}, B_{2}$, and $A_{2}$

In the light of Eqs. (7) and (A5), $B_{5}$ can be solved as follows:

$\mathrm{B}_{5}=\frac{\mathrm{f}_{5}\left(\mathrm{~T}_{\mathrm{c}}\right)}{\mathrm{T}_{\mathrm{c}}=\frac{\left\{0.8 \mathrm{RT}_{\mathrm{c}}\left[\left(\mathrm{V}_{\mathrm{c}}-\mathrm{b}\right) \mathrm{h}\right]^{4}-3 \mathrm{P}_{\mathrm{c}}\left[\left(\mathrm{V}_{\mathrm{c}}-\mathrm{b}\right) \mathrm{h}\right]^{5}\right\}}{\mathrm{T}_{\mathrm{c}}}}(\mathrm{A} 10)$

Each term of Eq. (20) is multiplied by $(V-b) h$ and then substitute $V=R T Z / P$ into the obtained formula, considering $B_{1}=R$, the following equation can be derived:

$(\mathrm{ZRT}-\mathrm{Pb}) \mathrm{h}=\mathrm{RT}+\sum_{\mathrm{i}=2}^{5} \frac{\mathrm{f}_{\mathrm{i}}(\mathrm{T})}{\left[\left(\frac{\mathrm{ZRT}}{\mathrm{P}}-\mathrm{b}\right) \mathrm{h}\right]^{\mathrm{i}-1}}(\mathrm{~A} 11)$

Then $Z$ differentiates partially to $P$ at a given temperature and it finally obtains Eq. (A12):

$\left(\frac{\mathrm{dZ}}{\mathrm{dP}}\right)_{\mathrm{T}}=\frac{\mathrm{bh}+\frac{\mathrm{f}_{2}(\mathrm{~T}) \mathrm{RTZ}}{\mathrm{hP}^{2}\left(\mathrm{~b}-\frac{\mathrm{RTZ}}{\mathrm{P}}\right)^{2}}-\frac{2 \mathrm{f}_{3}(\mathrm{~T}) \mathrm{RTZ}}{\mathrm{h}^{2} \mathrm{P}^{2}\left(\mathrm{~b}-\frac{\mathrm{RTZ}}{\mathrm{P}}\right)^{3}}+\frac{3 \mathrm{f}_{4}(\mathrm{~T}) \mathrm{RTZ}}{\mathrm{h}^{3} \mathrm{P}^{2}\left(\mathrm{~b}-\frac{\mathrm{RTZ}}{\mathrm{P}}\right)^{4}}-\frac{4 \mathrm{f}_{5}(\mathrm{~T}) \mathrm{RTZ}}{\mathrm{h}^{4} \mathrm{P}^{2}\left(\mathrm{~b}-\frac{\mathrm{RTZ}}{\mathrm{P}}\right)^{5}}}{\mathrm{hRT}+\frac{\mathrm{f}_{2}(\mathrm{~T}) \mathrm{RTZ}}{\mathrm{hP}\left(\mathrm{b}-\frac{\mathrm{RTZ}}{\mathrm{P}}\right)^{2}}-\frac{2 \mathrm{f}_{3}(\mathrm{~T}) \mathrm{RTZ}}{\mathrm{h}^{2} \mathrm{P}\left(\mathrm{b}-\frac{\mathrm{RTZ}}{\mathrm{P}}\right)^{3}}+\frac{3 \mathrm{f}_{4}(\mathrm{~T}) \mathrm{RTZ}}{\mathrm{h}^{3} \mathrm{P}\left(\mathrm{b}-\frac{\mathrm{RTZ}}{\mathrm{P}}\right)^{4}}-\frac{4 \mathrm{f}_{5}(\mathrm{~T}) \mathrm{RTZ}}{\mathrm{h}^{4} \mathrm{P}\left(\mathrm{b}-\frac{\mathrm{RTZ}}{\mathrm{P}}\right)^{5}}}(\mathrm{~A} 12)$

When $P=P_{r}=0, Z=1$, Eq. (A12) is simplified to the following form:

$\mathrm{f}_{2}(\mathrm{~T})=\left\{\left[\left(\frac{\mathrm{dZ}}{\mathrm{dP}}\right)_{\mathrm{P}_{\mathrm{r}}=0}\right] \frac{(\mathrm{RTh})^{2}}{\mathrm{P}_{\mathrm{c}}}\right\}-\mathrm{bRTh}^{2}(\mathrm{~A} 13)$

According to Eqs. (14) and (A13) at the point of $T=\mathrm{T}^{\prime}$, the following formula can be derived:

$\mathrm{f}_{2}\left(\mathrm{~T}^{\prime}\right)=\mathrm{A}_{2}+\mathrm{B}_{2} \mathrm{~T}^{\prime}+\mathrm{C}_{2} \mathrm{e}^{-5.475 \frac{\mathrm{T}^{\prime}}{\mathrm{T}_{\mathrm{c}}}}=\left\{\left[\mathrm{Z}_{\mathrm{c}}-1\right] \frac{\left(\mathrm{RT}^{\prime}\right)^{2}}{\mathrm{P}_{\mathrm{c}}}-\mathrm{bRT}^{\prime}\right\} \mathrm{h}^{2}(\mathrm{~A} 14)$

According to Eqs. (15) and (A13) at the point of $T=T_{B}$, the following formula can be derived:

$\mathrm{f}_{2}\left(\mathrm{~T}_{\mathrm{B}}\right)=\mathrm{A}_{2}+\mathrm{B}_{2} \mathrm{~T}_{\mathrm{B}}+\mathrm{C}_{2} \mathrm{e}^{-5.475 \frac{\mathrm{T}_{\mathrm{B}}}{\mathrm{T}_{\mathrm{c}}}}=-\mathrm{bRT}_{\mathrm{B}} \mathrm{h}^{2}(\mathrm{~A} 15)$ 
Meanwhile,

$\mathrm{f}_{2}\left(\mathrm{~T}_{\mathrm{c}}\right)=\mathrm{A}_{2}+\mathrm{B}_{2} \mathrm{~T}_{\mathrm{c}}+\mathrm{C}_{2} \mathrm{e}^{-5.475}=9 \mathrm{P}_{\mathrm{c}}\left[\left(\mathrm{V}_{\mathrm{c}}-\mathrm{b}\right) \mathrm{h}\right]^{2}-3.8 \mathrm{RT}_{\mathrm{c}}\left(\mathrm{V}_{\mathrm{c}}-\mathrm{b}\right) \mathrm{h}(\mathrm{A} 16)$

By combining Eqs. (A14), (A15) and (A16), the arithmetic solutions of $C_{2}, B_{2}$, and $A_{2}$ are finally deduced as follows:

$\mathrm{C}_{2}=\frac{\left[\mathrm{f}_{2}\left(\mathrm{~T}_{\mathrm{c}}\right)+\mathrm{bRT}^{\prime} \mathrm{h}^{2} \frac{\left(1-\mathrm{Z}_{\mathrm{c}}\right)}{\mathrm{P}_{\mathrm{C}}}\right]\left(\mathrm{T}_{\mathrm{B}}-\mathrm{T}_{\mathrm{c}}\right)+\left[\mathrm{f}_{2}\left(\mathrm{~T}_{\mathrm{c}}\right)+\mathrm{bRT}_{\mathrm{B}} \mathrm{h}^{2}\right]\left(\mathrm{T}_{\mathrm{c}}-\mathrm{T}^{\prime}\right)}{\left(\mathrm{e}^{-5.475}-\mathrm{e}^{\frac{-5.475 \mathrm{~T}^{\prime}}{\mathrm{T}_{\mathrm{C}}}}\right)\left(\mathrm{T}_{\mathrm{B}}-\mathrm{T}_{\mathrm{c}}\right)-\left(\mathrm{e}^{\frac{-5.475 \mathrm{~T}_{\mathrm{B}}}{\mathrm{T}_{\mathrm{C}}}}-\mathrm{e}^{-5.475}\right)\left(\mathrm{T}_{\mathrm{c}}-\mathrm{T}^{\prime}\right)}$

$\mathrm{B}_{2}=\frac{\left[-\mathrm{f}_{2}\left(\mathrm{~T}_{\mathrm{c}}\right)-\mathrm{bRT}_{\mathrm{B}} \mathrm{h}^{2}-\mathrm{C}_{2}\left(\mathrm{e}^{\frac{-5.475 \mathrm{~T}_{\mathrm{B}}}{\mathrm{T}_{\mathrm{C}}}}-\mathrm{e}^{-5.475}\right)\right]}{\mathrm{T}_{\mathrm{B}}-\mathrm{T}_{\mathrm{c}}}($

$\mathrm{A}_{2}=\mathrm{f}_{2}\left(\mathrm{~T}_{\mathrm{c}}\right)-\mathrm{B}_{2} \mathrm{~T}_{\mathrm{c}}-\mathrm{C}_{2} \mathrm{e}^{-5.475}(\mathrm{~A} 19)$

The solution of $B_{3}, A_{3}, C_{3}, A_{4}$ and $B_{4}$

By substituting Eqs. (3), (4), (5), (7) and (18) into the novel M-H EOS (20), then the first-order and second-order differential equations about $P$ with respect to $T$ at a given volume can be achieved as follows:

$$
\begin{aligned}
& \left(\frac{\mathrm{dP}}{\mathrm{dT}}\right)_{\mathrm{V}}=\frac{\mathrm{R}}{(\mathrm{V}-\mathrm{b}) \mathrm{h}}+\sum_{\mathrm{i}=2}^{5} \frac{\mathrm{B}_{\mathrm{i}}}{[(\mathrm{V}-\mathrm{b}) \mathrm{h}]^{1}}+\left(-\frac{5.475}{\mathrm{~T}_{\mathrm{c}}}\right)\left[\frac{\mathrm{C}_{2}}{[(\mathrm{~V}-\mathrm{b}) \mathrm{h}]^{2}}+\frac{\mathrm{C}_{3}}{[(\mathrm{~V}-\mathrm{b}) \mathrm{h}]^{3}}\right] \mathrm{e}^{\frac{-5.475 \mathrm{~T}}{\mathrm{~T}_{\mathrm{c}}}}(\mathrm{A} 20) \\
& \left(\frac{\mathrm{d}^{2} \mathrm{P}}{\mathrm{dT}^{2}}\right)_{\mathrm{V}}=\left(-\frac{5.475}{\mathrm{~T}_{\mathrm{c}}}\right)^{2}\left[\frac{\mathrm{C}_{2}}{[(\mathrm{~V}-\mathrm{b}) \mathrm{h}]^{2}}+\frac{\mathrm{C}_{3}}{[(\mathrm{~V}-\mathrm{b}) \mathrm{h}]^{3}}\right] \mathrm{e}^{\frac{-5.475 \mathrm{~T}}{\mathrm{~T}_{\mathrm{c}}}}(\mathrm{A} 21)
\end{aligned}
$$

According to the equations about Eqs. (16), (17), (18), (A20) and (A21), the following formulas can be achieved:

$\mathrm{C}_{3}=-\mathrm{C}_{2}\left(\mathrm{~V}_{\mathrm{c}}-\mathrm{b}\right) \mathrm{h}(\mathrm{A} 22)$

$\mathrm{B}_{3}=\mathrm{B}_{3}^{0}-\frac{\mathrm{B}_{4}}{\left(\mathrm{~V}_{\mathrm{c}}-\mathrm{b}\right) \mathrm{h}}(\mathrm{A} 23)$

$\mathrm{B}_{3}^{0}=\mathrm{m}\left[\left(\mathrm{V}_{\mathrm{c}}-\mathrm{b}\right) \mathrm{h}\right]^{3}-\mathrm{R}\left[\left(\mathrm{V}_{\mathrm{c}}-\mathrm{b}\right) \mathrm{h}\right]^{2}-\mathrm{B}_{2}\left(\mathrm{~V}_{\mathrm{c}}-\mathrm{b}\right) \mathrm{h}-\frac{\mathrm{B}_{5}}{\left[\left(\mathrm{~V}_{\mathrm{c}}-\mathrm{b}\right) \mathrm{h}\right]^{2}}(\mathrm{~A} 24)$

$\mathrm{A}_{3}=\mathrm{A}_{3}^{0}-\frac{\mathrm{B}_{4} \mathrm{~T}_{\mathrm{c}}}{\left(\mathrm{V}_{\mathrm{c}}-\mathrm{b}\right) \mathrm{h}}(\mathrm{A} 25)$

$\mathrm{A}_{3}^{0}=\mathrm{f}_{3}\left(\mathrm{~T}_{\mathrm{c}}\right)-\mathrm{B}_{3}^{0} \mathrm{~T}_{\mathrm{c}}-\mathrm{C}_{3} \mathrm{e}^{-5.475}(\mathrm{~A} 26)$

$\mathrm{A}_{4}=\mathrm{f}_{4}\left(\mathrm{~T}_{\mathrm{c}}\right)-\mathrm{B}_{4} \mathrm{~T}_{\mathrm{c}}(\mathrm{A} 27)$

By substituting $A_{2}, B_{2}, C_{2} ; A_{3}, B_{3}, C_{3} ; A_{4}, B_{4}$ and $B_{5}$ into the novel M-H EOS (20), the following equation can be derived:

$$
\mathrm{P}=\frac{\mathrm{RT}}{(\mathrm{V}-\mathrm{b}) \mathrm{h}}+\frac{\mathrm{A}_{2}+\mathrm{B}_{2} \mathrm{~T}+\mathrm{C}_{2} \mathrm{e}^{-5.475 \frac{\mathrm{T}}{T_{\mathrm{c}}}}}{[(\mathrm{V}-\mathrm{b}) \mathrm{h}]^{2}}+\frac{\mathrm{A}_{3}^{0}+\mathrm{B}_{3}^{0} \mathrm{~T}+\mathrm{C}_{3} \mathrm{e}^{-5.475} \frac{\mathrm{T}}{\mathrm{T}_{\mathrm{c}}}}{[(\mathrm{V}-\mathrm{b}) \mathrm{h}]^{3}}+\frac{\mathrm{f}_{4}\left(\mathrm{~T}_{\mathrm{c}}\right)}{[(\mathrm{V}-\mathrm{b}) \mathrm{h}]^{4}}+\frac{\mathrm{B}_{5} \mathrm{~T}}{[(\mathrm{~V}-\mathrm{b}) \mathrm{h}]^{5}}+\frac{\mathrm{B}_{4}\left(\mathrm{~V}-\mathrm{V}_{\mathrm{c}}\right)\left(\mathrm{T}_{\mathrm{c}}-\mathrm{T}\right)}{\left(\mathrm{V}_{\mathrm{c}}-\mathrm{b}\right)[(\mathrm{V}-\mathrm{b}) \mathrm{h}]^{4}}
$$

By introducing Eq. (A28) into Eq. (19), the definite integral about $V$ can be derived at a given vapor pressure and temperature $\left(P_{o}, T_{o}\right)$ :

$\mathrm{P}_{\mathrm{o}}\left(\mathrm{V}_{\mathrm{v}}-\mathrm{V}_{\mathrm{l}}\right)=$

$$
\left\{\begin{array}{c}
\frac{\mathrm{RT} \mathrm{T}_{\mathrm{o}}}{\mathrm{h}} \ln (\mathrm{V}-\mathrm{b})-\frac{\mathrm{A}_{2}+\mathrm{B}_{2} \mathrm{~T}_{\mathrm{o}}+\mathrm{C}_{2} \mathrm{e}^{-5.475 \frac{\mathrm{T}_{\mathrm{o}}}{\mathrm{T}_{\mathrm{c}}}}}{(\mathrm{V}-\mathrm{b}) \mathrm{h}^{2}}-\frac{\mathrm{A}_{3}^{0}+\mathrm{B}_{3}^{0} \mathrm{~T}+\mathrm{C}_{3} \mathrm{e}^{-5.475 \frac{\mathrm{T}_{\mathrm{o}}}{\mathrm{T}_{\mathrm{c}}}}}{2(\mathrm{~V}-\mathrm{b})^{2} \mathrm{~h}^{3}}-\frac{\mathrm{f}_{4}\left(\mathrm{~T}_{\mathrm{c}}\right)}{3(\mathrm{~V}-\mathrm{b})^{3} \mathrm{~h}^{4}} \\
-\frac{\mathrm{B}_{5} \mathrm{~T}_{\mathrm{o}}}{4(\mathrm{~V}-\mathrm{b})^{4} \mathrm{~h}^{5}}-\frac{\mathrm{B}_{4}}{\mathrm{~h}^{4}}\left[\frac{1}{2\left(\mathrm{~V}_{\mathrm{c}}-\mathrm{b}\right)(\mathrm{V}-\mathrm{b})^{2}}-\frac{1}{3(\mathrm{~V}-\mathrm{b})^{3}}\right]\left(\mathrm{T}_{\mathrm{c}}-\mathrm{T}_{\mathrm{o}}\right)
\end{array}\right\} V_{\mathrm{v}}
$$

Set $\Phi\left(\mathrm{V}, \mathrm{B}_{4}\right)$ is the function of volume and $B_{4}$, as follows:

$\Phi\left(\mathrm{V}, \mathrm{B}_{4}\right)=\mathrm{P}_{\mathrm{o}} \mathrm{V}-$ 


$$
\left\{\begin{array}{c}
\frac{R T_{o}}{h} \ln (V-b)-\frac{A_{2}+B_{2} T_{o}+C_{2} e^{-5.475} \frac{T_{o}}{T_{c}}}{(V-b) h^{2}}-\frac{A_{3}^{0}+B_{3}^{0} \mathrm{~T}+C_{3} e^{-5.475} \frac{T_{o}}{T_{c}}}{2(V-b)^{2} h^{3}}-\frac{f_{4}\left(T_{c}\right)}{3(V-b)^{3} h^{4}} \\
-\frac{B_{5} T_{o}}{4(V-b)^{4} h^{5}}-\frac{B_{4}}{h^{4}}\left[\frac{1}{2\left(V_{c}-b\right)(V-b)^{2}}-\frac{1}{3(V-b)^{3}}\right]\left(T_{c}-T_{o}\right)
\end{array}\right\}
$$

Set $f_{1 i}\left(V_{i}\right)$ and $f_{2 i}\left(V_{i}\right)$ as follows:

$f_{1 i}\left(V_{i}\right)=P_{o} V_{i}-\frac{R T_{o}}{h} \ln \left(V_{i}-b\right)+\frac{A_{2}+B_{2} T_{o}+C_{2} e^{-5.475} \frac{T_{o}}{T_{c}}}{\left(V_{i}-b\right) h^{2}}+\frac{A_{3}^{0}+B_{3}^{0} T+C_{3} e^{-5.475 \frac{T_{o}}{T_{c}}}}{2\left(V_{i}-b\right)^{2} h^{3}}+\frac{f_{4}\left(T_{c}\right)}{3\left(V_{i}-b\right)^{3} h^{4}}+\frac{B_{5} T_{o}}{4\left(V_{i}-b\right)^{4} h^{5}}(A 31)$

$\mathrm{f}_{2 \mathrm{i}}\left(\mathrm{V}_{\mathrm{i}}\right)=\frac{\left(\mathrm{T}_{\mathrm{c}}-\mathrm{T}_{\mathrm{o}}\right)}{\mathrm{h}^{4}}\left[\frac{1}{2\left(\mathrm{~V}_{\mathrm{c}}-\mathrm{b}\right)(\mathrm{V}-\mathrm{b})^{2}}-\frac{1}{3(\mathrm{~V}-\mathrm{b})^{3}}\right](\mathrm{A} 32)$

Due to $\Phi\left(\mathrm{V}_{\mathrm{v}}, \mathrm{B}_{4}\right)=\Phi\left(\mathrm{V}_{\mathrm{l}}, \mathrm{B}_{4}\right), B_{4}$ can be solved as the following formula shows:

$\mathrm{B}_{4}=\frac{\mathrm{f}_{1 \mathrm{v}}\left(\mathrm{V}_{\mathrm{v}}\right)-\mathrm{f}_{11}\left(\mathrm{~V}_{1}\right)}{\mathrm{f}_{2 \mathrm{v}}\left(\mathrm{V}_{\mathrm{v}}\right)-\mathrm{f}_{21}\left(\mathrm{~V}_{1}\right)}(\mathrm{A} 33)$

The remaining unsolved parameters: $A_{3}, B_{3}$ and $A_{4}$ can be solved through the application of $B_{4}$ achieved by Eq. (A33).

$\mathrm{A}_{3}=\mathrm{f}_{3}\left(\mathrm{~T}_{\mathrm{c}}\right)-\left\{\mathrm{m}\left[\left(\mathrm{V}_{\mathrm{c}}-\mathrm{b}\right) \mathrm{h}\right]^{3}-\mathrm{R}\left[\left(\mathrm{V}_{\mathrm{c}}-\mathrm{b}\right) \mathrm{h}\right]^{2}-\mathrm{B}_{2}\left(\mathrm{~V}_{\mathrm{c}}-\mathrm{b}\right) \mathrm{h}-\frac{\mathrm{B}_{5}}{\left[\left(\mathrm{~V}_{\mathrm{c}}-\mathrm{b}\right) \mathrm{h}\right]^{2}}\right\} \mathrm{T}_{\mathrm{c}}-\mathrm{C}_{3} \mathrm{e}^{-5.475}+\frac{\mathrm{B}_{4} \mathrm{~T}_{\mathrm{c}}}{\left(\mathrm{V}_{\mathrm{c}}-\mathrm{b}\right) \mathrm{h}}(\mathrm{A} 34)$

$\mathrm{B}_{3}=\mathrm{m}\left[\left(\mathrm{V}_{\mathrm{c}}-\mathrm{b}\right) \mathrm{h}\right]^{3}-\mathrm{R}\left[\left(\mathrm{V}_{\mathrm{c}}-\mathrm{b}\right) \mathrm{h}\right]^{2}-\mathrm{B}_{2}\left(\mathrm{~V}_{\mathrm{c}}-\mathrm{b}\right) \mathrm{h}-\frac{\mathrm{B}_{5}}{\left[\left(\mathrm{~V}_{\mathrm{c}}-\mathrm{b}\right) \mathrm{h}\right]^{2}}-\frac{\mathrm{B}_{4}}{\left(\mathrm{~V}_{\mathrm{c}}-\mathrm{b}\right) \mathrm{h}}(\mathrm{A} 35)$

$\mathrm{A}_{4}=\mathrm{f}_{4}\left(\mathrm{~T}_{\mathrm{c}}\right)-\mathrm{B}_{4} \mathrm{~T}_{\mathrm{c}}(\mathrm{A} 36)$

\section{APPENDIX II}

\section{THE DEFINITION AND SOLUTION OF OTHER RELATE PARAMETERS}

\section{The definition of $m$ and its solution}

The definition of $m$ can be found in Eq. (16). The solution of $m$ involves the solution of $M$ and the critical property of a given substance ${ }^{9,12}$.

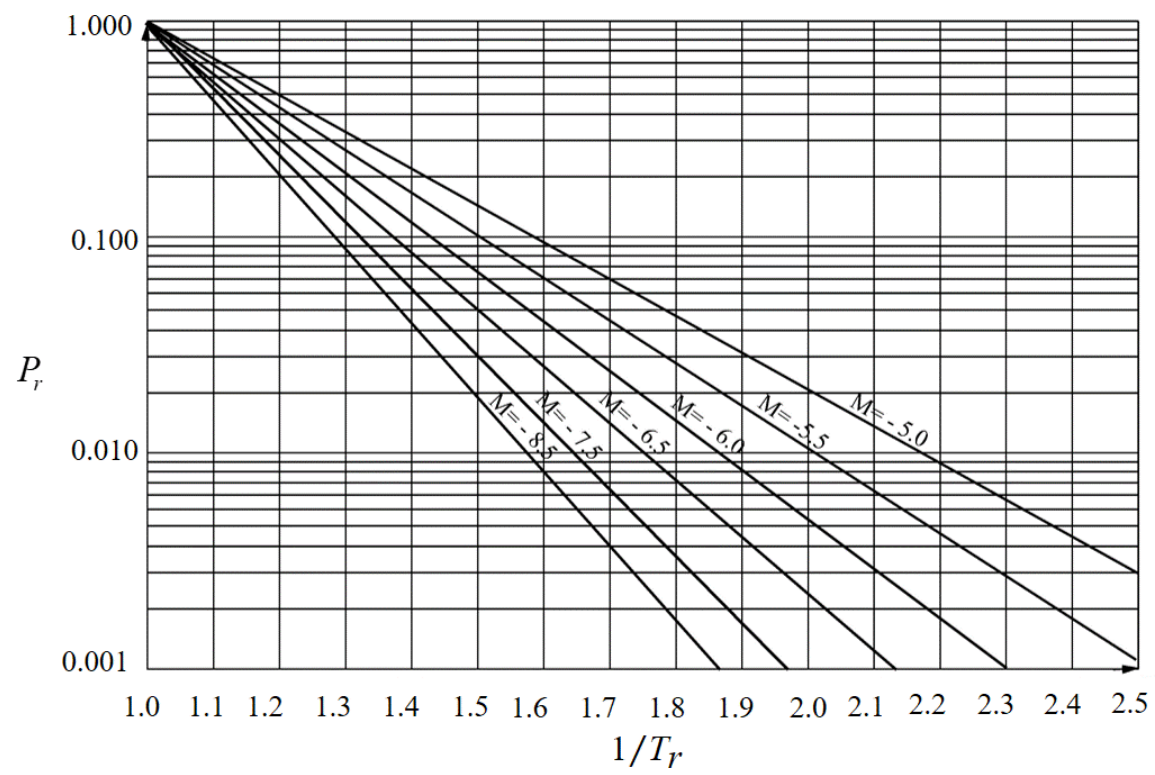

Figure A2Reduced vapor-pressure plot ${ }^{12}$

$M$ is defined as: 
$\frac{\mathrm{dP}}{\mathrm{P}_{\mathrm{r}}}=-\mathrm{M} \frac{\mathrm{d} \mathrm{T}_{\mathrm{r}}}{\mathrm{T}_{\mathrm{r}}^{2}}(\mathrm{~A} 37)$

The value of $M$ can be achieved by checking Figure A2 and then $m$ can be calculated by Eq. (16). The value of $m$ also could be achieved by the following equation while the precision is not as good as the former $\operatorname{method}^{9,12}$.

$\mathrm{m}=(5.82+4.92 \omega) \frac{\mathrm{P}_{\mathrm{c}}}{\mathrm{T}_{\mathrm{c}}} \quad(\mathrm{A} 38)$

$\omega$ is the eccentric factor for a given substance.

The definition of $T^{\prime}$ and its solution

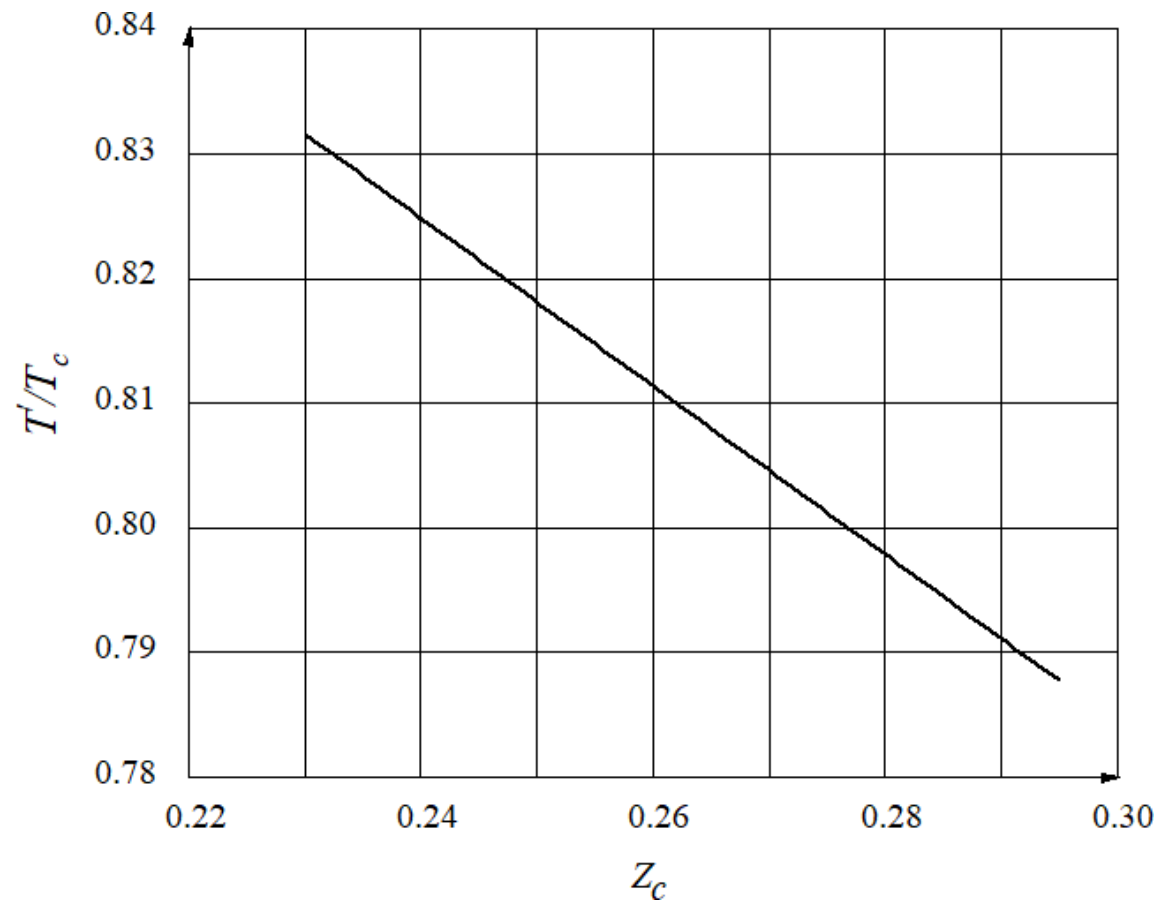

Figure A3 Relation schema between $T^{\prime} / T_{c}$ and $Z_{\mathrm{c}}{ }^{12}$

$T$ ' is a constant for a given substance, which approximates to $0.8 T_{c} . T^{\prime}$ can be achieved from Figure A3 . The following equation shows the relationship between $T^{\prime} / T_{\mathrm{c}}$ and $Z_{\mathrm{c}}{ }^{9,12}$ :

$\mathrm{T}^{\prime} / \mathrm{T}_{\mathrm{c}}=0.9869-0.6751 \mathrm{Z}_{\mathrm{c}}(\mathrm{A} 39)$ 


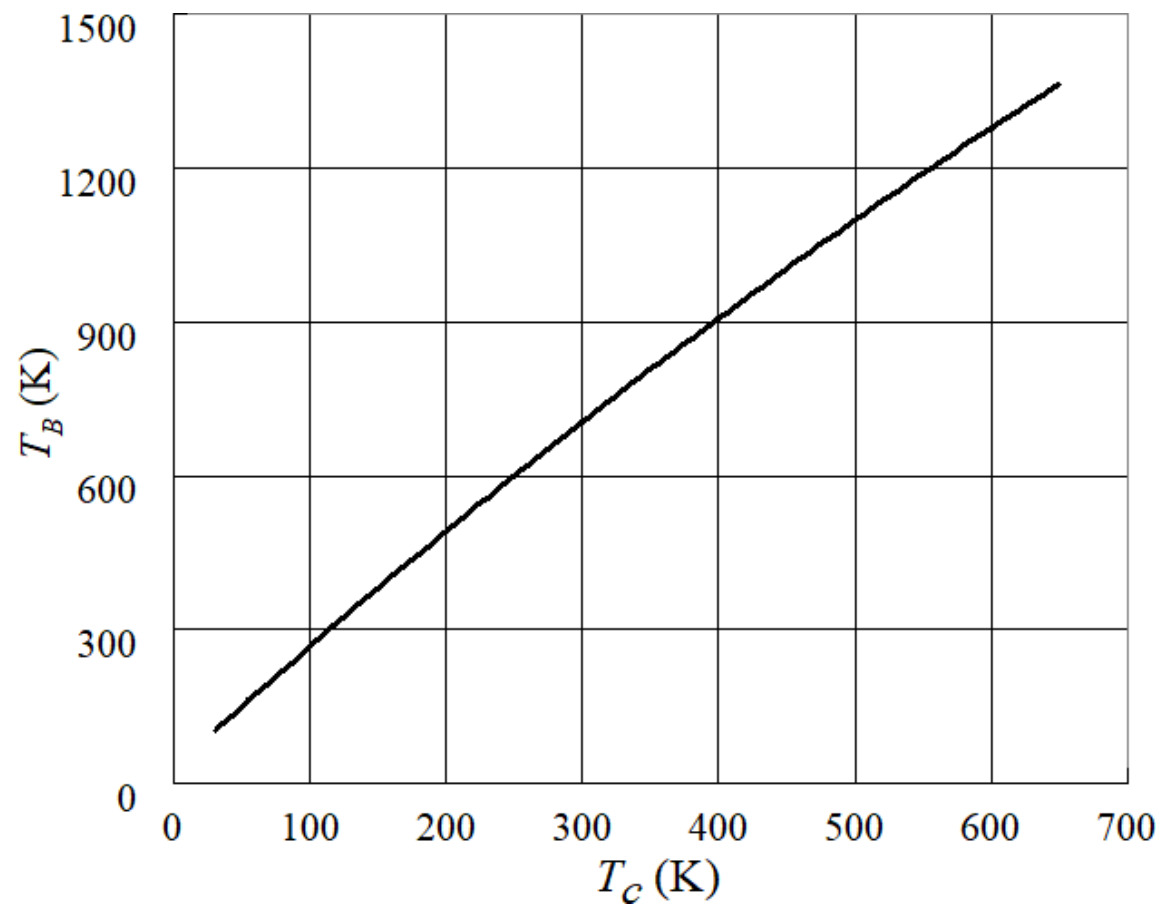

The definition of $T_{B}$ and the its solution

Figure A4Relation schema between $T_{B}$ and $T_{\mathrm{c}}{ }^{12}$

$T_{B}$ is Boyle-Point Temperature and can be achieved by checking Figure A4 . At the same time, it can be calculated by the following equation ${ }^{9,12}$ :

$\mathrm{T}_{\mathrm{B}}=30+2.42 \mathrm{~T}_{\mathrm{c}}-5.67 \times 10^{-4} \mathrm{~T}_{\mathrm{c}}^{2}(\mathrm{~A} 40)$

The definition of Boyle-Point Temperature is expressed as the following equation:

$\left(\frac{\partial \mathrm{Z}}{\partial \mathrm{P}}\right)_{\mathrm{T}_{\mathrm{B}}, \mathrm{P} \rightarrow 0}=0(\mathrm{~A} 41)$

\section{Hosted file}

Figure 1 Pressure-Volume diagram.tif available at https://authorea.com/users/303944/articles/ 434266-the-modification-of-the-martin-hou-equation-of-state-and-its-application-inliquid-phase-state

\section{Hosted file}

Figure A1 Relation schema between \selectlanguage\{greek\} \selectlanguage\{english\}and Zc.tif available at https://authorea.com/users/303944/articles/434266-the-modification-of-themartin-hou-equation-of-state-and-its-application-in-liquid-phase-state

\section{Hosted file}

Figure A2 Reduced vapor-pressure plot.tif available at https://authorea.com/users/ 303944/articles/434266-the-modification-of-the-martin-hou-equation-of-state-and-itsapplication-in-liquid-phase-state

\section{Hosted file}


Figure A3 Relation schema between T' And Zc.tif available at https://authorea.com/users/ 303944/articles/434266-the-modification-of-the-martin-hou-equation-of-state-and-itsapplication-in-liquid-phase-state

\section{Hosted file}

Figure A4 Relation schema between TB and Tc.tif available at https://authorea.com/users/ 303944/articles/434266-the-modification-of-the-martin-hou-equation-of-state-and-itsapplication-in-liquid-phase-state 